\title{
A DESCOBERTA DE UMA IDENTIDADE PÓS-COLONIAL EM ESSE CABELO, DE DJAIMILIA PEREIRA DE ALMEIDA
}

\author{
THE DISCOVERY OF A POST-COLONIAL \\ IDENTITY IN DJAIMILIA PEREIRA DE \\ ALMEIDA'S ESSE CABELO
}

Sandra Sousa ${ }^{1}$

\section{RESUMO}

Neste ensaio, pretendo analisar como o cabelo, parte do corpo escolhida por Djaimilia Pereira de Almeida como foco da sua obra Esse cabelo (2015), entra em diálogo com questões de gênero, de sexualidade, de classe, raça e etnicidade no Portugal pós-colonial.

PALAVRAS-CHAVE: cabelo; género; pós-colonialismo

\section{ABSTRACT}

In this essay I analyze the way in which the representation of hair, the part of the body chosen by Djaimilia Pereira de Almeida to be the focal point of her novel Esse cabelo (2015), enables a dialog among questions of gender, sexuality, class, race and ethnicity in Post-colonial Portugal.

KEYWORDS: hair; gender; post-colonialism 
No seu recente livro Portugal a lápis de cor. A Sul de uma pós-colonialidade, Sheila Khan faz uma análise sociológica de Portugal após o processo de descolonização das suas possessões africanas. De acordo com a autora, Portugal acolheu no seu território "outros rostos, outras vidas com outras vivências, outras narrativas e outros modos de estar e ser", e "estas outras presenças humanas permanecem, ainda, socialmente ignoradas e marginalizadas não obstante a existência de uma profilaxia politicamente correcta de Portugal como país 'lusotropicalista' e, como tal, multicultural" (KHAN, 2015, p. 42-43). Khan lança pertinentes questões: por que continuam a persistir em Portugal ausências e silêncios, ou seja, por que não existe a incorporação das vozes dos Outros nos discursos oficiais e não oficiais?; que aprendizagens retirou Portugal da sua experiência colonial para posteriormente se iniciar como nação pós-colonial? Numa frase, por que nada (ou muito pouco) parece ter mudado em termos de atitude em relação ao Outro que, como é enfatizado por Khan ao longo da obra, vive mesmo aqui ao lado?

O livro Esse cabelo (2015), de Djaimilia Pereira de Almeida, parece vir em socorro da ansiedade de Khan, ao colmatar, pelo menos em certa medida, uma ausência nessa vasta costa de silêncios africanos em Portugal. Esse cabelo é, no entanto, diferente da maioria da escrita que até agora tem saído em Portugal sobre questões coloniais e pós-coloniais, não apenas pela razão de ser uma obra de difícil catalogação - romance, ensaio, memória, autobiografia -, mas pela forma como a história entre Portugal e África nos é contada. Djaimilia conta a sua história, que é também a história da sua família, num misto de memória e ficção, através de uma parte do corpo: o cabelo. Neste ensaio, pretendo analisar como essa parte do corpo escolhida por Djaimilia como foco da sua obra entra em diálogo com questões de gênero, de sexualidade, de classe, raça e etnicidade no Portugal pós-colonial.

Teóricas feministas, juntamente com teóricos de raça, têm feito, ao longo das décadas, importantes contribuições para uma filosofia de embodiment, assegurando que a atenção ao corpo desempenha um papel central no pensamento político e social. Os estudos produzidos nesse sentido proporcionam uma narrativa geral das relações entre corpos e identidades pessoais. Em Visible identities, race, gender, and the self, Linda Alcoff usa a expressão visible identities para identificar categorias de identidade que se encontram ancoradas em características corporais físicas. Alcoff oferece um relato que integra as categorias de identidade social com as experiências que as pessoas têm dos seus corpos e dos outros. Tendo como foco identidades raciais e de género, Alcoff torna clara a forma como características físicas (cor, cabelo, nariz, seios, genitais) estão investidas de significado que se torna parte da nossa imediata experiência perceptiva das mesmas. Se- 
gundo Alcoff, “Tanto raça como sexo [...] são sobretudo e definitivamente físicos, marcados no e pelo corpo, vividos como uma experiência material, visíveis como fenómenos de superfície e determinantes de estatuto económico e político"2 (ALCOFF, 2006, p. 102). Devido à realidade material das características e à relação imediata da nossa resposta perceptiva, os significados anexados a tais características tornam-se naturalizados. O facto de que são produto de modos de percepção aprendidos não nos é evidente, uma vez que tais práticas perceptivas se tornaram habituais e são resistentes a mudança. Alcoff afirma que "a consciência de raça e género produz maneirismos corporais habituais que se sentem como naturais e se tornam inconscientes quando usados prolongadamente" ${ }^{\otimes}$ (ALCOFF, 2006, p. 108).

Como este e outros estudos apontam, "o assunto dos corpos femininos e da sexualidade feminidade é altamente carregado" "SULEIMAN, 1985, p. 7). Susan Suleiman refere que a questão da corporalidade e sexualidade femininas "tem implicações tanto para a política - isto é, para as relações de poder e controlo que governam uma sociedade - e para a literatura, ou seja, a produção de construções verbais que de alguma forma refletem ou ajudam a criar essas relações" (SULEIMAN, 1985, p. 7).

Já na primeira frase de seu prólogo, o livro de Djamilia estabelece uma relação íntima entre a questão política e identitária de pertencimento nacional e a corporalidade contida na noção de nacionalidade. É uma afirmação aparentemente simples: "Estar grato por ter um país assemelha-se a estar grato por ter um braço” (ALMEIDA, 2015, s/p.). No entanto, ela leva-nos a ponderar sobre as suas ramificações, principalmente devido à questão que lhe segue imediatamente: "Como escreveria se perdesse o braço?" (ALMEIDA, 2015, s/p.). A perda do braço ligada a uma noção de gratidão tanto por uma parte essencial do corpo como por ter um país levanta, por associação, a questão de o que sucederia caso se perdesse um país. Ou, ainda: como se escreveria caso se perdesse um país? Como escrever se o meu corpo não estiver submetido a um país e, por extensão, à cultura do mesmo? Pode, contudo, escrever-se sem um braço e sem um país quando o objetivo é a busca de um sentido de pleno pertencimento e de identidade, que se reclama, também ela, como fazendo parte desse país. Ao contrário das "testemunhas [que me] afiançam que sou a mais portuguesa dos portugueses da minha família," (ALMEIDA, 2015, s/p.) como refere a personagem principal ainda no prólogo, essa experiência de nacionalidade não é sentida nem vivida por Mila - a protagonista que por vezes se confunde com a autora - de forma inquestionável. Uma das particularidades do seu corpo, o cabelo crespo, conta uma mais complexa história individual - que também é colectiva - de nacionalidade portuguesa e de integração de ex-colonos, africanos e imigrantes em Portugal: "A verdade é que a história do meu cabelo crespo cruza a história de pelo menos dois países e, panoramicamente, a história indirecta da relação entre vários continentes: uma geopolítica” (ALMEIDA, 2015, p. 13). 
Toril Moi sugere, em What is woman? and other essays, a categoria do "lived body", que pode capturar a forma como características materiais dos nossos corpos desempenham um papel no nosso sentido subjetivo do "eu." Um corpo "vivido" ou "em vivência" é sempre um corpo em determinada situação, um corpo submetido a cultura. Assim, em Esse cabelo, a vivência de Mila entre Angola e Portugal se materializa subjetivamente na experiência do seu cabelo, como ela própria afirma: "Talvez o livro do cabelo esteja já escrito, problema resolvido, mas não o livro do meu cabelo [...]” (ALMEIDA, 2015, p. 14).

A biografia do cabelo de Mila leva a que o leitor se embrenhe não apenas no sentido de busca pessoal da protagonista - a busca da sua origem -, mas igualmente na tentativa de compreensão de um país que tem vindo a silenciar e a colocar à margem todas as histórias de todos os cabelos crespos que nele vivem. Djamilia, como ela própria afirma em entrevista ao jornal Público, sente-se

totalmente lisboeta, mas uma pessoa como eu é sempre uma rapariga africana em Lisboa. Não tenho propriamente uma casa aonde regressar. Mesmo que eu ensaiasse um regresso, não tenho aonde ir. Estou como muitas outras pessoas numa espécie de limbo da origem de que não nos conseguimos muito bem desenvencilhar. (LUCAS, 2015, s/p.)

A sua história tem a particularidade de ser a de um corpo feminino que cresceu e viveu em Lisboa com a sua família portuguesa, com algumas idas a Angola para visitar a mãe durante o verão, o que a afasta da maioria dos casos de africanos em Portugal. No entanto, o seu corpo, se quisermos, a sua materialidade, afasta-a desse sentimento de pertença a um país que sempre teve dificuldade em abarcar o seu sangue negro, preferindo uma falsa imagem de brancura. A África de Mila (Djaimilia?) é, consequentemente, não mais do que uma falta ou uma sobra:

A casa assombrada que é todo o cabeleireiro para a rapariga que sou é muitas vezes o que me sobra de África e da história da dignidade dos meus antepassados. Sobra-me, porém, em lamento e escovadelas reparadoras, regressada a casa do "salão", como diz a minha mãe, e em não levar demasiado a mal o trabalho destas cabeleireiras cuja implacabilidade e incompetência nunca consegui decidir-me a confrontar. Tudo aquilo com que posso contar é com catálogo de salões, com a sua história de transformações étnicas no Portugal que me calhou [...] (ALMEIDA, 2015, p. 14-15)

A história do cabelo de Mila é também a história da situação da mulher africana e emigrante em Portugal que, como podemos observar no estudo de Augusto Nascimento sobre a Associação das Mulheres de São Tomé e Príncipe em Portugal (2012), é invocada como uma vida dura, de dificuldades familiares, emocionais e económicas que se acentuam com a crise, e na qual o racismo que por vezes sentem na pele é evidente. A sua história "da entrega da aprendizagem da feminilidade" (ALMEIDA, 2015, 
p. 15), partilhada com outras mulheres africanas em situações semelhantes ou diferenciadas, "não é o conto de fadas da mestiçagem, mas é uma história de reparação" (ALMEIDA, 2015, p. 15). A alusão ao mito lusotropicalista do corpo mulato, símbolo da multirracialidade portuguesa, criado por Gilberto Freyre é mais do que óbvia. Giorgio de Marchis afirma a propósito que "a Lisboa africana fica encoberta por um nevoeiro branco que a 'miopia selectiva' dos lisboetas tradicionais não descortina e que não permite inscrever a presença africana intra muros" (MARCHIS, 2009, p. 23). E Miguel Vale de Almeida aponta, em tom semi-irónico: "A narrativa da mistura baseia-se na dádiva que recusa o contra-dom: alguns portugueses ter-se-iam misturado com africanos; no processo teriam oferecido materiais culturais; mas nada seria suposto 'retornar' a Portugal, nada cultural e muito menos étnico-racial” (ALMEIDA, 2007, p. 364). No entanto, esse retorno ou regresso aconteceu, mas a caracterização étnica que coloca seres humanos na periferia e estabelece graus de humanização entre pessoas continua: "Em tempos disseram-me que sou uma 'mulata das pedras', de mau cabelo e segunda categoria. Esta expressão ofusca-me sempre com a reminiscência visual de rochas da praia: rochas lodosas em que se escorrega e é difícil andar descalço" (ALMEIDA, 2015, p. 16).

A história deste cabelo é uma história de racismo em relação à pele escura em geral; racismo silencioso ou naturalizado, como afirma Paulo Granjo, e que

faz com que muitíssimas pessoas, regressadas a Portugal e passadas décadas, não consigam entender como racista a sociedade em que viveram, por considerarem que nela se comportaram de forma humana e decente para com os subalternos. Não questionando nem conseguindo questionar, ao olharem para trás, essa subalternidade e os seus fundamentos (GRANJO, 2009, p. 118)

Essa forma natural de se viver e interpretar o racismo foi, sem dúvida, transposta para uma vivência pós-colonial portuguesa que insiste em olhar para Mila como uma menina "muito clássica" (ALMEIDA, 2015, p. 15) e que se cola à pele dos africanos que se imaginam portugueses, como o avô Castro, angolano, a quem

Ninguém olhou nunca para ele, este autodeclarado cava-
quista, o portuguesão, como ficou conhecido na juventude,
que proferia "centra a bola, seu macaco" referindo-se a fute-
bolistas negros e dividia as pessoas por espécies de animais
da selva, caracterizando-se a si mesmo enquanto "o tipo ma-
caco": aquele que aguarda o fim das conversas para exibir a
sua sabedoria. (ALMEIDA, 2015, p. 15).

Personagem singular, o avô Castro chega a Portugal em 1984 e numa situação também ela singular, a de tratar de um dos seus filhos nascido com uma perna mais curta do que a outra. Como afirma Mila, "não veio por isso enquanto imigrante, para trabalhar, mas como pai, acabando 
por ficar mais tempo que o previsto e depois [...] até ao fim da sua vida" (ALMEIDA, 2015, p. 20). O livro lança o leitor neste momento, e a partir de um facto corpóreo - uma perna maior do que a outra -, para a situação constrangedora dos enfermos da África de expressão portuguesa em Lisboa. Na descrição dos seus corpos doentes, amputados, massacrados apercebemo-nos de uma outra forma de marginalização. Estes corpos fisicamente deteriorados não vão além dos limites que circundam o hospital, habitando pensões baratas, pouco limpas e de cheiro podre que funcionam mais como prisões. O corpo aqui surge como uma metáfora do fim do Império; um Império cujos membros quebraram, em ferida aberta, sem braços para acolher os seus filhos, também eles despojados. Mila é eloquente na sua descrição destes habitantes de um espaço que lhes é negado na totalidade:

À entrada da Pensão Covilhã, mesmo na esquina da Casa de Amigos de Paredes de Coura, os doentes tomam um ar de Lisboa. Trazem um penso num dos olhos, uma gangrena na coxa, o braço guardado num gesso já puído e tatuado, sob o qual se coçam com um pauzinho chinês. São os despojos do império, Camões de ocasião embora tenham apenas nove anos, escusados à mortalidade infantil para o que lhes parecem umas férias urbanas e, à semelhança de todos, destinados a conhecer de Portugal, com alguma sorte, apenas o mundo de onde vieram. (ALMEIDA, 2015, p. 20-21)

A discriminação racial encontra-se ainda presente em lugares mais subtis, tais como na publicidade das embalagens de desfrisante, ao qual cabeleireiras submetiam o cabelo indomável de Mila, "anunciando, na variedade infantil, crianças negras de cabelos lisos, risonhas, modelos de vida instantâneos" (ALMEIDA, 2015, p. 28). Ao mesmo tempo que nos mesmos pacotes se via uma "menina que, segundo asseverava a minha mãe, não era negra [...]” (ALMEIDA, 2015, p. 29). Mila é, deste modo, criada numa ideia padronizada (fictícia) de beleza e de mulher. Para seu infortúnio, não herdara o cabelo da sua avó portuguesa, Lúcia, ao contrário das primas que, ainda crianças, não podiam "por enquanto adivinhar a bênção que lhe[s] tinha calhado: uma herança viva e vã” (ALMEIDA, 2015, p. 33). A ideia de pertença, de origem, de nacionalidade surge novamente associada ao conceito de corporalidade:

Um primo de visita comenta que sou "uma angolana mais que falsa”. Tem razão. Para meu grande pesar, não é aceitável declarar à polícia de fronteira que a minha pátria é o cabelo de Lúcia. Saber de onde venho, no entanto, pareceria crucial para a história do meu cabelo, rememoração permanente não de esquinas ventosas de Oeiras por volta de mil novecentos e noventa, não de pedras e cheiros, mas de uma origem concreta, uma origem no sentido habitual. (ALMEIDA, 2015, p. 34)

A angústia (ou problema?) fundamental de Mila - presumivel- 
mente a da maioria das mulheres que não se encaixam nas normas de beleza ditadas por determinada sociedade em que vivem - é pensar-se através de um estereótipo. Como vários estudos indicam, é normalmente fácil para uma sociedade fazer a transição de um estereótipo para formas de racismo quando ideias estereotipadas são continuamente reforçadas. Estereótipos baseados em raça ou nacionalidade servem para perpetuar discriminação. Nascida de um cruzamento de diferentes etnias, culturas e valores, a sua tendência é querer fazer parte da norma, uma vez que isso lhe facilitaria a inserção e lhe evitaria comentários não apenas de desconhecidos, mas dos seus próprios familiares, tal como o repreendedor da sua avó branca: "Então Mila, quando é que tratas esse cabelo?" (ALMEIDA, 2015, p. 45). Nas palavras da narradora:

Que preferível seria um cosmopolitismo autêntico a um paroquial cheiro de senhora, vestígio do cruzamento das vidas de um comerciante português errante pelo Congo, um pescador albino de M’banza Kongo, católicas anciãs de Seia, cristãos-novos maçons de Castelo Branco, meus ancestrais? (ALMEIDA, 2015, p. 34)

No entanto, ser fruto desta intersecção e ter desconhecimento da sua origem não é de todo negativo. Representar a diferença na sociedade portuguesa traz a Mila algumas vantagens, como ela própria indica: "A minha declarada ignorância quanto à toponímia de Luanda talvez tenha a única vantagem de me proteger de um cortejo de lugares-comuns da lusofonia, substituídos, todavia, por outros, a que nem sempre sou sensível, e que vigio como um guarda-nocturno obeso" (ALMEIDA, 2015, p. 34). A crítica deixada por Mila ao conceito de lusofonia como espaço integrante, o da comunidade imaginada formulado por Benedict Anderson, é notória. A propósito surgem as palavras de Lurdes Macedo, quando ela afirma que

a lusofonia tem sido, tradicionalmente, entendida à luz de um conjunto de dimensões que se afiguram cada vez mais redutoras: a dimensão geográfica, que reúne os oito países da Comunidade de Países de Língua Portuguesa (CPLP); a dimensão política, que se confina ao conjunto das comunidades de língua portuguesa espalhadas pelo mundo; e, finalmente, a dimensão histórico-cultural relacionada com o legado português em vários pontos do globo durante a expansão marítima e o império colonial. Como não perceber em cada uma destas dimensões, e citando Moisés de Lemos Martins, "um espaço de refúgio imaginário" e de "nostalgia imperial"? (MACEDO, 2011, s/p)

Esse espaço de "refúgio imaginário", mas que se pretende real, global e plural, cria sujeitos "despenteados," destinados a inventar metáforas de si mesmos. Tal é o exemplo da aproximação que Mila faz entre os conceitos de loucura e cidadania, a respeito do seu avô Castro, o já referido angolano que se identifica como português e cuja integração na sociedade portuguesa - sociedade lusófona apenas imaginada - se prova difícil devido à sua óbvia diferença: 
O medo de a cultura de um país poder sucumbir às mãos dos imigrantes reflectia-se, em todo o seu ridículo, na toada elegíaca dos espirituais bacongo cantados para si mesmo pelo meu avô Castro no autocarro que o levava à Cimov, temendo a curiosidade dos passageiros e que eles pensassem que falava sozinho, tomando-o por louco. (Disse-me estar a dar as boas-vindas à morte, quando lhe perguntei porque cantava.) Temer ser tomado por louco é contudo sinal de não se estar em casa. (ALMEIDA, 2015, p. 44; ênfase minha)

A loucura que inevitavelmente é associada a um desvio da norma é aqui transposta para um estado social não apenas de não pertença, mas de nacionalidade outra, de imigrantes que, como loucos, não se adequam à sanidade do grupo mais vasto, ou seja, são vistos pelos de dentro como desvios que se devem manter à margem, equivalendo os seus bairros a temidos hospícios. Por outro lado, os imigrantes sentem que devem exercer sobre si mesmos autocontrole, vivendo no medo de serem estigmatizados. A rotina diária de trabalho do avô Castro na Cimov é comparada à de um escravo no tempo do colonialismo; embora em Lisboa dos anos 80/90, vestígios desse mundo imperial do passado ainda se fazem sentir:

Sob a camisa e as calças velhas, bem podia ter regressado de autocarro de um campo de algodão, o meu avô, seco e musculado, abdominais definidos, incoerentes. Saído às cinco da manhã, seriam oito da noite em São Gens no seu regresso, carregado com um termo enchido com as sobras da cantina da Cimov: batatas cozidas e algumas carcaças rijas. (ALMEIDA, 2015, p. 44-45)

Maria da Luz, a avó negra, por seu turno, vive Lisboa a partir da invalidez do seu corpo, resultado de uma trombose que a deixou imobilizada ainda jovem. A sua história na cidade seria, nas palavras de Mila, "uma biografia monótona de um braço, de uma perna" (ALMEIDA, 2015, p. 46), cuja imobilidade simboliza a não participação numa comunidade outra, apenas observada do ponto de vista do espectador, "sentada a uma mesa, ou à janela, admirando ao longe uma colina que a separava da Amadora" (ALMEIDA, 2015, p. 45). A história de Maria da Luz, que, em oposição à avó branca, se orgulhava do cabelo de Mila, é aquilo que a narradora descreve como podendo ser contada como uma história negativa:

a partir dos sítios aonde nunca foi, da Lisboa que nunca viria a conhecer, do autocarro em que nunca entraria, do colorido das ruas em que nunca andou desviando o olhar do homem-elefante omnipresente. [...] Não creio que a Mamã tenha visto alguma vez um dos pombos do Rossio, um dos seus loucos, o rio Tejo, a ponte, o Chiado, o Colombo. Penso agora que Maria da Luz terá encontrado encanto no movimento da roupa. A roupa ao vento foi para ela Portugal. (ALMEIDA, 2015, p. 46; ênfase minha)

Todos os personagens da vida de Mila, familiares de vivência intercontinental, têm de Lisboa apenas um "conceito amputado" (ALMEI- 
DA, 2015, p. 47), pois o acesso à plenitude desse corpo encontra-se-lhes vedado, como também os seus corpos e a sua vida se encontram vedados aos lisboetas. A certa altura da narrativa, Mila coloca uma interessante questão, num imperfeito do conjuntivo que demarca a impossibilidade de tal facto se realizar, mas que abre um espaço ilimitado de sugestões que, no entanto, a narradora deixa apenas a pairar na página do livro: "e se fossem eles [os lisboetas] os invisíveis?” (ALMEIDA, 2015, 47). A história seria, certamente, outra.

Referir invisibilidade é notar a ausência, não total mas significativa, da mãe de Mila na narrativa. O leitor não pode deixar de sentir esta carência na vida de Mila, que se afirma com as esporádicas referências à mãe. Da sua vida, da sua história, pouco ou nada se sabe além de indícios de que deve ter engravidado jovem - sem idade suficiente para assumir a responsabilidade de criar uma filha -, uma vez que sempre que vinha a Lisboa visitar a filha regressava "cada vez mais adulta" (ALMEIDA, 2015, p.75); uma mãe que, segundo o relato de Mila, se confunde com ela e com ela enuncia uma troca de papéis. Sente-se em Mila essa falta da mãe na confissão de acumular, em criança, sacos de plástico com brinquedos e desenhos que queria guardar apenas para a mãe; a ansiedade de uma criança de malas feitas, apesar de ser feliz, pronta para partir assim que a mãe a viesse buscar.

A relação entre as duas conforma-se a períodos de quinze dias ora em Portugal ora em Luanda, passados num misto de alegria, timidez e sonambulismo. Nas palavras de Mila, "Éramos duas estranhas, embora ela me secasse quando eu saía do banho e me vestisse, me ensinasse a pôr loção no corpo comentando o aspecto do meu púbis e apesar de uma de nós ter sobre a outra responsabilidade" (ALMEIDA, 2015, p. 78). O curto espaço de tempo passado em Luanda não permite, no entanto, que Mila se sinta totalmente à vontade e inserida neste espaço: "Se estivéssemos em Luanda, eu passava as tardes à janela da varanda, exibindo o penteado sempre renovado; ou ia ao pão à esquina, recado cumprido a correr, temendo que dessem por mim, e tentando mudar de sotaque quando falava com as quitandeiras" (ALMEIDA, 2015, p. 78). O cabelo continua mesmo em Luanda a ser parte da sua diferença. Estar em paz com esta parte do seu corpo, apercebe-se Mila anos mais tarde através da pergunta oblíqua da mãe, feita ao telefone e na distância que as separava, sobre o seu cabelo, é uma forma de se encontrar consigo mesma (ALMEIDA, 2015, 80).

No seu percurso narrativo, a protagonista fala-nos ainda de uma "alienação ancestral" que "surge na história do cabelo como qualquer coisa a que se exige silêncio" (ALMEIDA, 2015, p. 16). Alienação e silêncio surgem aqui como caracterizações simbólicas de uma história colonial que não fez outra coisa senão apagar a individualidade pessoal e colectiva do ser colonizado. Alienação e silêncio aludindo ainda para o lugar para onde é remetido o ser pós-colonial em Portugal. Sheila Khan, em relação ao défice de atenção em relação a tudo o que veio de ultramar, afirma que 
[esse] défice [...] resulta de uma certa tendência portuguesa de não saber encarar e aceitar o Outro como seu próximo e, de um certo modo, como sua parcela histórica, social e cultural, pois, em muitos aspectos como observara Eduardo Lourenço (2001), esquecemo-nos do passado, quisemos isso sim cortar com o nosso passado africano e, imediatamente, dentro dessa desmedida de imaginação de centro nos direcionarmos para outro centro de auto-representação e de identificação, que se espraiou e se concentrou no horizonte europeu. (KHAN, 2015, p. 76-77)

O livro de Djaimilia Pereira de Almeida vem resgatar um lugar de pertencimento africano na cultura e sociedade portuguesas. A procura através da memória - com as suas falhas, esquecimentos, ficções - desse ponto fulcral que é o da origem remete o leitor para questões que estão para além da busca individual da protagonista, embora ela se surpreenda com a "coincidência entre o que sou e a narração da minha origem" (ALMEIDA, 2015, p. 34). Mila acaba por nos responder, de forma eloquente, como resolve esse problema de identidade e origem, embrenhando-se em si mesma. Vale a pena a citação completa:

"Onde deixei a Mila?", pergunto-me, como se procurasse as chaves de casa. Terei ficado na Beira, em sessenta e sete, lendo um jornal em voz alta à sombra de um mamoeiro, ou serei aquele borrão de tinta na fotografia de uma barragem também em Moçambique? Serei as nódoas de água sobre a secretária do avô Manuel; uma caneta na mala do avô Castro; a pulga no colchão em São Gens? Encontrar uma pessoa pode ser sinal de que a procurámos. Parece-me todavia que "encontrar" não é um resultado previsto de "procurar" quando falamos de pessoas. Encontrar-me a mim é mais parecido com encontrar uma pulga quando se procurava um borrão; encontrar uma nódoa de água quando se procurava uma chave; encontrar uma caneta quando se procurava uma pessoa. O que se encontra reconfigura o que se procurava. A procura de uma origem e de uma identidade não reconstitui a minha origem nem descobre a minha identidade. Uma pessoa apenas se encontra a si mesma por acaso. (ALMEIDA, 2015, p. 137)

É na tentativa de se descobrir através da "narração elíptica da biografia inacabada do meu cabelo" (ALMEIDA, 2015, p. 149), ou seja, dessa parte do seu corpo que a distingue, que Mila acaba por descobrir que "encerrei um capítulo, possivelmente o da infância do meu cabelo" (p. 148). No entanto, Djaimilia abriu outros capítulos que não apenas o da sua história individual que nos permitem pensar em outras configurações de género, raça e nacionalidade através do corpo. Através de um simples elemento caracterizador de aparência física, toda uma história surge, uma história de seres humanos que ocupam um espaço nacional português, mas, porque se diferenciam em cor, aspecto físico, género e raízes ances- 
trais, são relegados à invisibilidade e/ou à caricatura. É necessário e imperativo resgatar esses outros cabelos para a arena principal do debate em Portugal pós-colonial se pretendemos uma sociedade mais justa, igualitária e acolhedora da diferença.

\section{REFERÊNCIAS BIBLIOGRÁFICAS}

ALCOFF, Linda Martin. Visible identities, race, gender, and the self. New York: Oxford University Press, 2006.

ALMEIDA, Djaimilia Pereira. Esse cabelo. Lisboa: Teorema, 2015.

ALMEIDA, Miguel Vale de. Comentário. In: SANCHES, Manuela Ribeiro (org.). Portugal não é um País Pequeno. Contar o Império na Pós-Colonialidade. Lisboa: Cotovia, 2007. p. 359-367.

GRANJO, Paulo. Um amor colonial. Alpiarça: Edições Cosmos, 2009.

KHAN, Sheila. Portugal a lápis de cor. A Sul de uma pós-colonialidade. Coimbra: Almedina, 2015.

LUCAS, Isabel. Entrevista "Uma rapariga africana em Lisboa." Público, 02/10/2015. Disponível em: https://www.publico.pt/culturaipsilon/noticia/uma-rapariga-africana-em-lisboa-1709352

MACEDO, Lurdes. Lusofonia, identidade e diversidade na sociedade em rede. Buala, 02/01/2011. Disponível em: http://www.buala.org/pt/a-ler/ lusofonia-identidade-e-diversidade-na-sociedade-em-rede

MARCHIS, Girogio de. Lisboa africana. Experiências de integração e desintegração. In: GROSSEGESSE, Orlando; THORAU, Henry (eds). .A procura da Lisboa africana. Da encenação do império ultramarino às realidades suburbanas. Braga: Universidade do Minho, Centro de Estudos Humanísticos, 2009. p. 17-29.

MOI, Toril. What is woman? and other essays. Oxford: Oxford University Press, 1999.

NASCIMENTO, Augusto. O associativismo feminino são-tomense em Lisboa: uma questão de género? Cadernos de estudos africanos, 24, p. 117-139, 2012. Disponível em: http://cea.revues.org/650

SULEIMAN, Susan Rubin. (Re)writing the body: the politics and poetics of female eroticism. The female body in western culture. Ed. Susan Rubin Suleiman. Cambridge, MA, Harvard University Press, 1986. 


\section{NOTAS}

1 Doutorada em Estudos Luso-Brasileiros pela Brown University, Sandra Sousa é Professora Assistente na University of Central Florida. Tem ensaios e recensões publicados nos EUA, no Brasil e em Portugal. É autora do livro Ficções do Outro: Império, Raça e Subjectividade no Moçambique Colonial (Esfera do Caos, 2015).

2 "Both race and sex [...] are most definitely physical, marked on and through the body, lived as a material experience, visible as surface phenomena and determinant of economic and political status"

3 "race and gender consciousness produce habitual bodily mannerisms that feel natural and become unconscious after long use"

4 "the question of women's bodies and women's sexuality is a highly loaded one."

5 "has implications both for politics - that is, for the relations of power and control that govern a society - and for literature, or the production of verbal constructs that in some ways reflect and in some ways help to create those relations"

6 Note-se que Mila apenas nasce em 1982. A data remete para a presença dos avós que emigraram para a Beira, Moçambique, antes de se mudarem para Angola. 